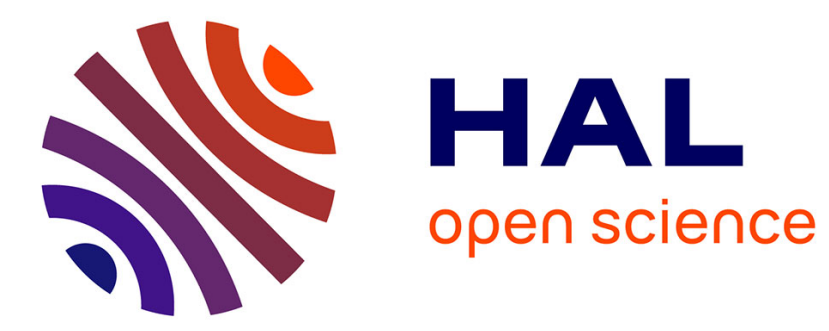

\title{
Accurate electron channeling contrast analysis of a low angle sub-grain boundary
}

Haithem Mansour, M. A. Crimp, Nathalie Gey, Nabila Maloufi

\section{To cite this version:}

Haithem Mansour, M. A. Crimp, Nathalie Gey, Nabila Maloufi. Accurate electron channeling contrast analysis of a low angle sub-grain boundary. Scripta Materialia, 2015, 109, pp.76-79. 10.1016/j.scriptamat.2015.07.023 . hal-01513866

\section{HAL Id: hal-01513866 https://hal.univ-lorraine.fr/hal-01513866}

Submitted on 13 Dec 2019

HAL is a multi-disciplinary open access archive for the deposit and dissemination of scientific research documents, whether they are published or not. The documents may come from teaching and research institutions in France or abroad, or from public or private research centers.
L'archive ouverte pluridisciplinaire HAL, est destinée au dépôt et à la diffusion de documents scientifiques de niveau recherche, publiés ou non, émanant des établissements d'enseignement et de recherche français ou étrangers, des laboratoires publics ou privés. 


\title{
Accurate electron channeling contrast analysis of a low angle sub-grain boundary
}

\author{
H. Mansour ${ }^{\mathrm{a}, *}$, M.A. Crimp ${ }^{\mathrm{b}}, \mathrm{N} . \mathrm{Gey}^{\mathrm{a}, \mathrm{c}}$, N. Maloufi ${ }^{\mathrm{a}, \mathrm{c}, *}$ \\ ${ }^{a}$ Laboratoire d'Étude des Microstructures et de Mécanique des Matériaux (LEM3), Université de Lorraine, 57045 Metz, France \\ ${ }^{\mathrm{b}}$ Michigan State University, Department of Chemical Engineering E Materials Science, 428 S. Shaw Lane, East Lansing, MI 48824, United States \\ ${ }^{\mathrm{c}}$ Laboratory of Excellence on Design of Alloy Metals for low-mAss Structures (DAMAS), Université de Lorraine, France
}

\section{A R T I C L E I N F O}

\section{Keywords:}

HR-SACP assisted ECCI

Electron backscattering diffraction (EBSD)

Grain boundary structure

Misorientation

Dislocation structure

\begin{abstract}
A B S T R A C T
High resolution selected area channeling pattern (HR-SACP) assisted accurate electron channeling contrast imaging (A-ECCI) was used to unambiguously characterize the structure of a low angle grain boundary in an interstitial-free-steel. The boundary dislocations were characterized using TEM-style contrast analysis. The boundary was determined to be tilt in nature with a misorientation angle of $0.13^{\circ}$ consistent with the HR-SACP measurements. The results were verified using high accuracy electron backscatter diffraction (EBSD), confirming the approach as a discriminating tool for assessing low angle boundaries.
\end{abstract}

The development and structure of low angle grain boundaries play critical roles in a wide range of materials processes and behaviors. Examples of where such boundaries are inexorably linked to behavior include the development of low energy dislocation structures during static and dynamic recovery, creation of dislocation cell structures during fatigue deformation, and many creep processes.

In order to fully understand many of these phenomena, it is necessary to characterize low angle boundaries in terms of their misorientations and dislocation structure. In many cases such studies have been carried out using transmission electron microscopy (TEM) in conjunction with electron diffraction, which offers direct imaging combined with high accuracy orientation measurements [1-9]. Nevertheless, TEM is limited by the need to create, and the potential artifacts of, thin foils $[10,11]$.

Over the past two decades electron backscattered diffraction (EBSD) and associated orientation mapping has been used to rapidly map crystal orientations at the surfaces of bulk materials, allowing sub grain structures to be readily observed over large areas $[12,13]$. However, this approach is limited in that it does not allow direct imaging and characterization of the defects associated with low angle boundaries and, in most cases, is hampered

\footnotetext{
* Corresponding authors at: Laboratoire d'Étude des Microstructures et de Mécanique des Matériaux (LEM3), Université de Lorraine, 57045 Metz, France (N. Maloufi).

E-mail addresses: haithem.mansour@univ-lorraine.fr(H.Mansour),nabila.maloufi@ univ-lorraine.fr (N. Maloufi).
}

by the inherent limits in precision of the Hough transform based approach to solving EBSD patterns [14-16].

Electron channeling contrast imaging (ECCI) is a powerful technique for observing and characterizing crystallographic defect such as dislocations, stacking faults, and grain boundaries in scanning electron microscopy (SEM) [17-23]. In order to detect defects, ECCI uses the fact that the backscattered electron yield is very sensitive to the angle between the incident beam and the crystal lattice. ECC can be optimized by controlling the channeling conditions to so called two-beam conditions, allowing the characterization of crystallographic planes responsible for the channeling effect and facilitating TEM-style contrast analysis [17,24,25].

A novel approach to control the channeling conditions for performing ECCI with an accuracy of $0.04^{\circ}$ has recently been developed. This approach is based on an innovative procedure for collecting high angular and spatial resolution (about $500 \mathrm{~nm}$ ) selected area channeling patterns (HR-SACPs) on the GEMINI-type electron column [26]. This technique, called Accurate ECCI (A-ECCI), was applied to unambiguously characterize screw dislocations in fine-grained IF-Steel using the $\mathbf{g} \cdot \mathbf{b}=0$ invisibility criterion [17].

In this study we present a new method for characterizing the nature of low angle boundaries by combining the direct imaging and characterization of dislocations using ECCI with high precision misorientation measurement using HR-SACPs. A-ECCI is used to analyze a low sub-grain boundary located in a specific grain of a polycrystalline bcc $2 \%$ Si IF steel slightly deformed in tension. Following the deformation process the specimen surface was first 
mechanically polished and then finished electrolytically. The study was carried out on a Zeiss AURIGA 40 FIB SEM, where HR-SACPs and ECC images were collected using an $11 \mathrm{~mm}^{2}$ four-quadrant Si-diode backscattered electron detector. The microscope was operated at $20 \mathrm{kV}$ and a $7 \mathrm{~mm}$ working distance. Prior to the HR-SACP collection, the sample was tilted to $70^{\circ}$ to facilitate determination of the orientation of the region of interest by EBSD. Since A-ECCI is carried out at low tilt, simulated EBSD data were used to approximate the orientation of the crystal of interest at 0 tilt. Specific channeling conditions were then accurately established by HR-SACP in conjunction with tilt and rotation of the sample.

Fig. 1a shows an HR-SACP taken from the grain of interest. This HR-SACP, indicated by the white square, is superimposed on a Kikuchi pattern dynamically simulated from orientation data determined by EBSD using the "Esprit DynamicS" software from Bruker. The position of the un-rocked beam, corresponding also to the microscope optic axis, is identified by a cross, and indicates a beam direction close to [232]. The coincidence between the experimentally collected HR-SACP and the surrounding simulated EBSD pattern is remarkable and allows precise determination of the orientation of the crystal relative to the optic axis, facilitating the establishment of two-beam channeling conditions.

The ECC image of the grain (Fig. 1b) reveals contrast from dislocations in relation with carbide particles throughout the structure. The change in the grain contrast from dark to bright and the series of aligned dislocations clearly reveal the location of the sub-boundary. Fig. 1b-3 shows a magnified secondary electron image of the sub-grain boundary with the particles indicated by

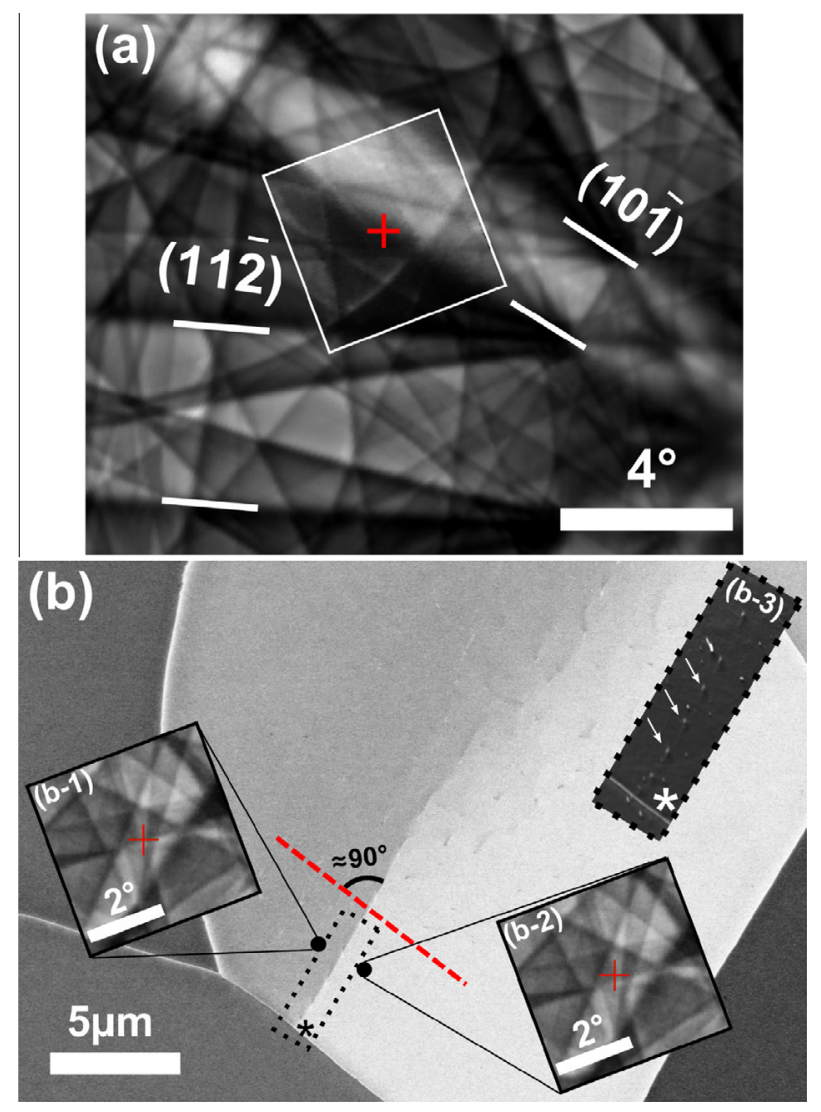

Fig. 1. (a) HR-SACP superimposed on a dynamical Kikuchi pattern simulated with the "Esprit DynamicS" software from Bruker. The red crosses in the HR-SACPs indicate the microscope optic axis. (b) ECC image of a sub-grain boundary showing HR-SACPs acquired from each side of the boundary reveals the direction of pattern shift (dotted red line) and the misorientation angle $\left(\approx 0.13^{\circ}\right.$ ). (For interpretation of the references to color in this figure legend, the reader is referred to the web version of this article.) white arrows close to the positions of the dislocations in the boundary.

Two HR-SACPs (b-1 and b-2), collected from the indicated areas on either side of the boundary, are also shown Fig. $1 \mathrm{~b}$. Superposition of the two HR-SACPs using the image analysis software "ImageJ" indicates that the direction of pattern shift is almost perpendicular to the sub-boundary trace, consistent with a tilt boundary made up of dislocation lines roughly parallel to the sample surface. Cross-correlation of the images shows the shift is 3.08 pixels. Knowing that the HR-SACPs are composed of $101 \times 101$ pixels and have an angular range of $\approx 4.4^{\circ}$ (at $\mathrm{WD}=7 \mathrm{~mm}$ ), this shift corresponds to a disorientation across the sub-grain boundary of $\approx 0.13^{\circ}$ between the points indicated.

Dislocations in bcc IF-steel are expected to have a Burgers vector $b=1 / 2<111\rangle$. Fig. 2 shows an HR-SACP assisted A-ECCI analysis of the dislocations making up the sub-grain boundary. Fig. 2a shows HR-SACPs of four channeling conditions used in the analysis superimposed on a dynamical simulation of the Kikuchi pattern for $0^{\circ}$ tilt. The sample was tilted up to $20^{\circ}$ and rotated to reach the different channeling conditions ( $g$-vectors), images of which are shown in Fig. 2b-e. According to Wilkinson et al. [27] the visibility of depth of dislocations in ECC images is approximately $5 \xi_{\mathrm{g}}$, where $\xi_{\mathrm{g}}$ is the extinction distance of the diffracted wave. At $20 \mathrm{kV}$ with $g=(01-1)$ the extinction distance is $\xi_{\mathrm{g}}=14.2 \mathrm{~nm}$. Using the projected length of the dislocations along the boundary $(\approx 480 \mathrm{~nm})$ and using a visibility depth of dislocations of $5 \xi_{\mathrm{g}}=71 \mathrm{~nm}$, the inclination angle of the dislocations line was approximated to be $\approx 8^{\circ}$ from the surface. The dislocation line direction, characterized by fading dashed lines that indicate the sense of inclination, is plotted on the stereographic projection in Fig. 2f. The trace and inclination correspond to the $[10-1]$ direction, indicating the dislocations are not $<111\rangle$ screw dislocations. The dislocations were characterized applying the $\mathbf{g} \cdot \mathbf{b}=0$ and $\mathbf{g} \cdot \mathbf{b x} \mathbf{u}=0$ invisibility criteria, as shown in Fig. 2b-e. In Fig. 2b, c and d the dislocations are visible for $\mathbf{g}=(01-1), \mathbf{g}=(1-10)$ and $\mathbf{g}=(1-21)$ respectively, but disappear with $\mathbf{g}=(10-1)$ in Fig. $2 \mathrm{e}$, which satisfies $\mathbf{g} \cdot \mathbf{b x u}=0$ for the dislocations being edge in character with a Burgers vector $\mathbf{b}=[1-11]$ and a line direction of $[10-1]$. The direction of the Burgers vector is plotted as a dashed green line in the stereographic projection, in Fig. $2 \mathrm{f}$.

Once the dislocations have been characterized the nature of the boundary can be evaluated. Knowing the distance between the dislocations emergence points, measured on the ECC image (averaging $\approx 1010 \mathrm{~nm}$ ), and the inclination angle of the dislocations lines $\left(\approx 8^{\circ}\right)$, the perpendicular spacing between the individual [10-1] dislocation lines making up the boundary was determined to be about $D \approx 146 \mathrm{~nm}$. With a lattice parameter of $0.29 \mathrm{~nm}$ resulting in a $1 / 2<111>$ Burgers vector of $0.25 \mathrm{~nm}$, a misorientation across the boundary can be estimated as $\theta \approx 0.1^{\circ}$, based on $D \approx b / \theta$.

A high accuracy EBSD map was acquired around the sub-grain boundary using an Oxford instruments EBSD system with a step size of $60 \mathrm{~nm}$ (this system uses hyperbola matching of the bands to enhance the accuracy, over simple Hough transform methods, to $\approx 0.05^{\circ}$ ) [28]. The disorientation relative to a reference pixel, labeled $\mathrm{R}$, in the bottom of the grain is plotted in Fig. 3, revealing the existence of the sub-grain boundary and the misorientation variation in the grain of interest. A number of different areas are labeled in Fig. 3. The misorientations between these areas were determined (the orientations were determined by averaging over 220 EBSD pixels in each area). The misorientation across the boundary, measured between points A1 and B2 (approximately the locations of the HR-SACPs in Fig. $1 \mathrm{~b}-1$ and $\mathrm{b}-2$ ) is $\approx 0.12^{\circ}$.

The misorientation across the boundary measured by high accuracy EBSD is very consistent with that measured by HR-SACPs $\left(\approx 0.13^{\circ}\right)$ and is comparable with the misorientation calculated based on the characterization of the dislocations in the boundary $\left(\approx 0.1^{\circ}\right)$. 

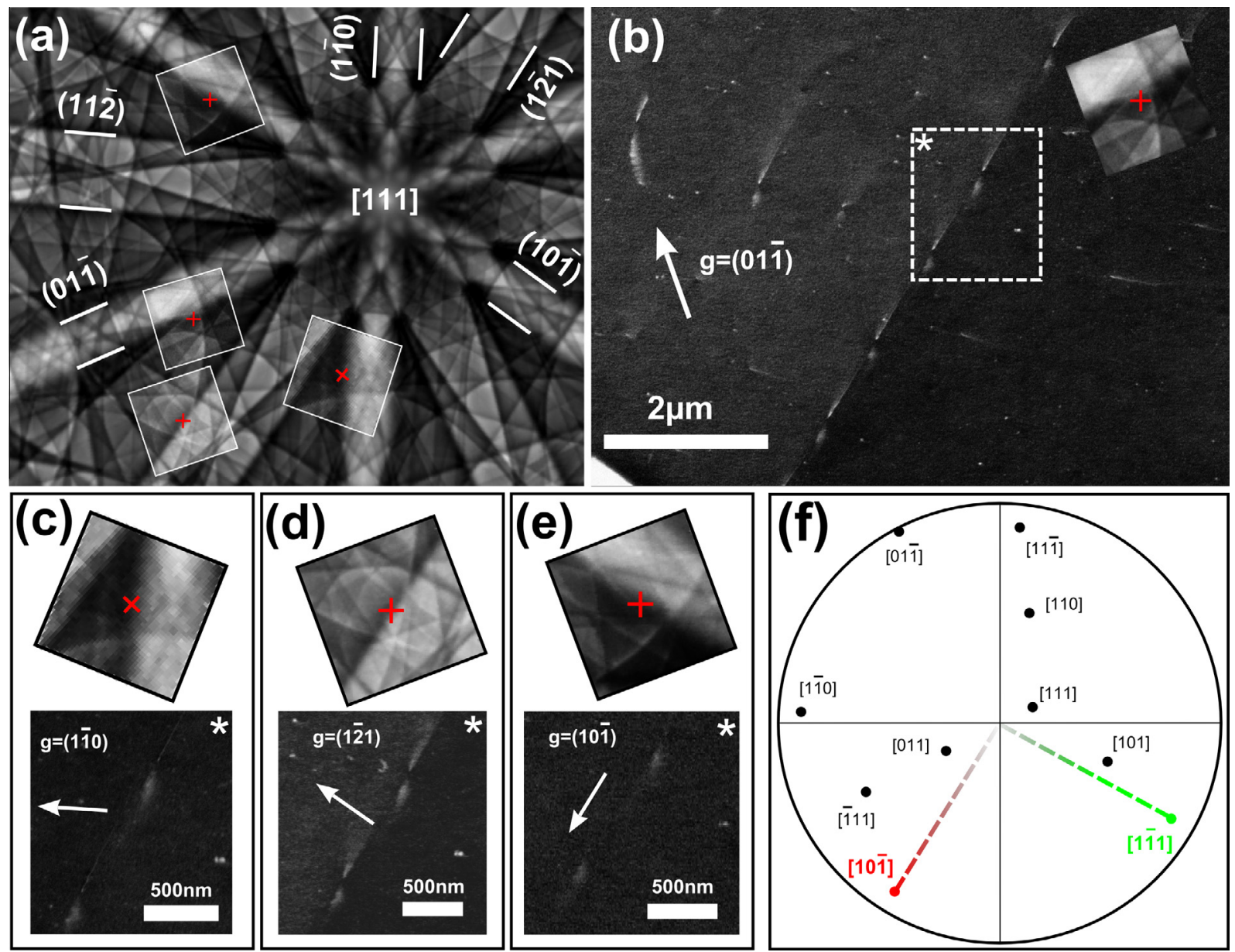

Fig. 2. Characterization of a sub-grain boundary using A-ECCI. (a) Four HR-SACPs superimposed on a dynamically simulated Kikuchi pattern. (b-e) HR-SACPs and A-ECCI images used for carrying out Burgers vector analysis of the boundary dislocations using $g \cdot b=0$ and $g$. $(b x u)=0$ invisibility criteria. (f) Stereographic projection showing $\{111\}$ and $\{110\}$ poles. The fading dashed red and green lines represent the direction of the inclined edge dislocation line [10-1] and Burgers vector [1 -11$]$ respectively. (For interpretation of the references to colour in this figure legend, the reader is referred to the web version of this article.)

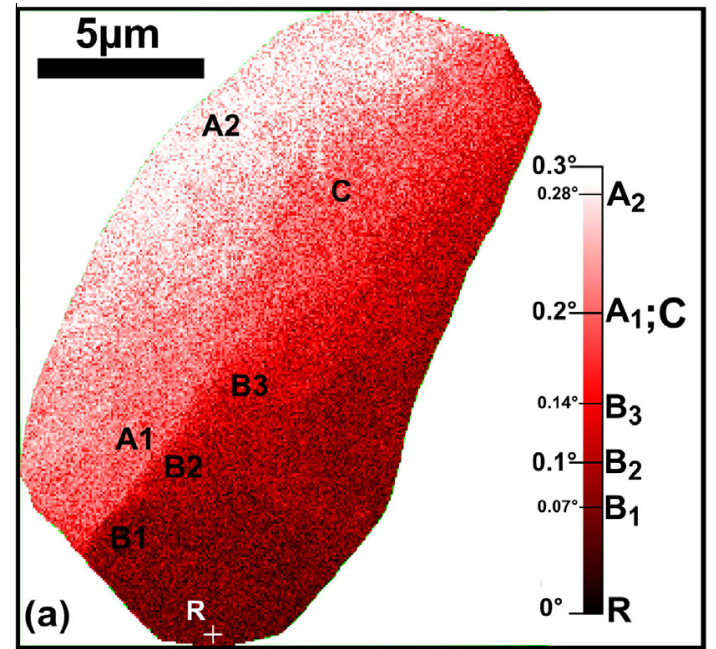

Fig. 3. EBSD map of the grain containing the sub-grain boundary, measured with a step size of $60 \mathrm{~nm}$. The misorientation relative to point $\mathrm{R}$ in the bottom of the grain is plotted using a scale from $0^{\circ}$ to $0.3^{\circ}$. The misorientation across the sub-boundary was measured by averaging the orientations in the areas A1 and B2.

It should be noted that there is some variation in the misorientation along the boundary. This can be clearly seen in Fig. 3, and is revealed by comparison of the high accuracy EBSD measurements taken at a number of other locations noted in the grain. For example, the misorientation between areas $\mathrm{B} 1$ and $\mathrm{B} 3$ is $\approx 0.08^{\circ}$. This variation in misorientation is consistent with the spacing between the boundary dislocations decreasing from the center of the grain towards the lower left of the Fig. $2 b$ and may also be the reason that the calculated misorientation does not result in a closer match with the measured misorientation. In fact, the boundary studied in this particular grain is very similar to a wedge disclination centered at the terminus of the sub-grain boundary at the center of the grain. If the spacing of the dislocations in the boundary were equal along the length of the boundary the result would be a perfect wedge disclination with a line direction parallel to the dislocation line direction and a constant misorientation across the boundary [29-31].

In summary, a very low angle sub-grain boundary in a polycrystalline bcc $2 \%$ Si IF-steel slightly deformed in tension was characterized using the new procedure combining HR-SACP and A-ECCI. HR-SACPs, with angular resolution of $0.04^{\circ}$ and spatial resolution better than $500 \mathrm{~nm}$, were acquired from each side of the boundary, revealing the tilt character of the boundary with a misorientation angle $\approx 0.13^{\circ}$. TEM style $\mathbf{g} \cdot \mathbf{b}=0$ and $\mathbf{g} \cdot \mathbf{b} \times \mathbf{u}=0$ contrast criteria were used to determine the Burgers vector and edge character of the dislocations. Based on these characteristics and the dislocation spacing, the misorientation angle of the boundary was calculated to be $\approx 0.1^{\circ}$, in good agreement with HR-SACP measurements. The misorientation results are consistent with high accuracy EBSD 
measurements of the misorientation across the boundary. Small variations in misorientation along the boundary observed with both HR-SACPs and high accuracy EBSD correspond with variations in dislocation spacing along the boundary, and indicate that the boundary is an imperfect wedge disclination. This work shows that HR-SACP combined with A-ECCI is a powerful tool for characterizing crystal defects and associated small misorientations, typically carried out using TEM, in the near surface region of bulk materials.

\section{Acknowledgements}

The authors would like to acknowledge S. Allain (IJL) for the helpful discussions and the University of Lorraine and LABEX DAMAS for the financial support of invited Professor M.A. Crimp.

\section{References}

[1] X. Huang, Scr. Mater. 60 (12) (2009) 1078-1082.

[2] B.L. Li, W.Q. Cao, Q. Liu, W. Liu, Mater. Sci. Eng., A 356 (2003) 37-42.

[3] D. Vanderschueren, N. Yoshinaga, K. Koyama, ISIJ Int. 36 (1996) 1046-1054.

[4] T. Ogawa, N. Maruyama, N. Sugiura, N. Yoshinaga, ISIJ Int. 50 (2010) 469-475.

[5] O. Saray, G. Purcek, I. Karaman, T. Neindorf, H.J. Maier, Mater. Sci. Eng., A 528 (2011) 6573-6583.

[6] S. Itoh, K. Nakazawa, T. Matsunaga, Y. Matsukawa, Y. Satoh, H. Abe, ISIJ Int. 54 (2014) 1729-1734.

[7] K. Máthis, T. Krajňák, M. Janeček, M. Dopita, H.S. Kim, Int. J. Mater. Res. 100 (2009) 834-837.

[8] J.F.C. Lins, H.R.Z. Sandim, H.J. Kestenbach, J. Mater. Sci. 42 (2007) 6572-6577.
[9] J.F.C. Lins, H.R.Z. Sandim, H.J. Kestenbach, Mater. Sci. Eng., A 457 (2007) 205218.

[10] L. Reimer, H. Kohl, Transmission Electron Microscopy Physics of Image Formation, 2008.

[11] M.A. Crimp, Microsc. Res. Tech. 69 (2006) 374-381.

[12] A.A. Gazder, W. Cao, C.H.J. Davies, E.V. Pereloma, Mater. Sci. Eng., A 497 (2008) $341-352$.

[13] A. Oudin, P.D. Hodgson, M.R. Barnett, Mater. Sci. Eng., A 486 (2008) 72-79.

[14] S.I. Wright, M.M. Nowell, D.P. Field, Microsc. Microanal. 17 (2011) 316-329.

[15] F.J. Humphreys, J. Mater. Sci. 36 (2001) 3833-3854.

[16] A.J. Wilkinson, P.B. Hirsch, Micron 28 (1997) 279-308.

[17] H. Mansour, J. Guyon, M.A. Crimp, N. Gey, B. Beausir, N. Maloufi, Scr. Mater. 84-85 (2014) 11-14.

[18] A. Barnoush, Acta Mater. 60 (2012) 1268-1277.

[19] A. Weidner, H. Biermann, Philos. Mag. 95 (2015) 759-793.

[20] Y.N. Picard, R. Kamaladasa, M. De Graef, N.T. Nuhfer, W.J. Mershon, T. Owens, L. Sedlacek, F. Lopour, Micros. Today 20 (2012) 12-16.

[21] J. Ahmed, S.G. Roberts, A.J. Wilkinson, Philos. Mag. 86 (2006) 4965-4981.

[22] S. Yamasaki, M. Mitsuhara, K. Ikeda, S. Hata, H. Nakashima, Scr. Mater. 101 (2015) 80-83.

[23] S. Zaefferer, N.-N. Elhami, Acta Mater. 75 (2014) 20-50.

[24] M.A. Crimp, B.A. Simkin, B.C. Ng, Philos. Mag. Lett. 81 (2001) 833-837.

[25] J.l. Zhang, S. Zaefferer, D. Raabe, Mater. Sci. Eng., A 636 (2015) 231-242.

[26] J. Guyon, H. Mansour, N. Gey, M.A. Crimp, S. Chalal, N. Maloufi, Ultramicroscopy 149 (2015) 34-44.

[27] A.J. Wilkinson, G.R. Anstis, J.T. Czernuszka, N.J. Long, P.B. Hirsch, Philos. Mag. A 68 (1993) 59-80.

[28] K. Thomsen, N.H. Schmidt, A. Bewick, K. Larsen, J. Goulden, Application note, AZtecHKL.

[29] M.J. Marcinkowski, Acta Crystallogr. A 33 (1977) 865-872.

[30] M. Kleman, J. Friedel, Rev. Mod. Phys. 80 (2008) 61-115.

[31] P. Klimanek, V. Klemm, A.E. Romanov, M. Seefeldt, Adv. Eng. Mater. 3 (2001) $877-884$. 